GDVERNANCE: Jurnal IImiah Kajian Politik Lokal dan Pembangunan

ISSN: 2406-8721 (Media Cetak) dan ISSN: 2406-8985 (Media Online)

Volume 7 Nomor 4 Juni 2021

\title{
NILAI-NILAI KEKUASAAN DALAM UKIRAN RUMAH TUO DI KELURAHAN KAMPUNG BARUH KECAMATAN TABIR KABUPATEN MERANGIN
}

\author{
Mulia Jaya ${ }^{1}$, Dwi Pradana Ariska ${ }^{2}$ \\ Program Studi Ilmu Pemerintahan Fakultas Ilmu Sosial dan Ilmu Politik \\ Universitas Muara Bungo. Jalan. Diponegoro No. 27. Kabupaten Bungo, Provinsi Jambi. \\ Email: lakes_krc@yahoo.co.id
}

\begin{abstract}
The values of power possessed by traditional holders or ninik mamak in the Bungo Malay community can be seen from their position in the tuo house. Tuo's house is one of the cultural relics of ancient Malay, Jambi's house is synonymous with Old Malay customs. The method used in this research is a qualitative research method which is a case study. Research informants were selected by purposive sampling method. The results of the study found that the values of power in the carving of the tuo house in Kampung Baruh Village, Tabir District, Merangin Regency, can be seen from the carvings on the tuo house ornaments, including: Carving of Keluk Paku (Pakis Wood) means that every development actor (leader) must be able to protect the The function and role it carries, Tampuk Manggis Carving means that the inner tribe shows politeness, sweet-faced hospitality to any guests who come. Carved Rope Philosophy of a strong bond and close kinship in the family, Carving Mensinding Gulung Paku (Pakis) showing the boundaries between mamak grandmothers, traditional elders, religious leaders with family and guest rooms, Carving Roots related to inner tribes if married their children from elements (matched) from their own family or from the same tribe. The efforts of the Merangin Regency Government in preserving the existence of tuo houses in Kampung Baruh Village, Tabir District, Merangin Regency, include making the area attractive, improving facilities and infrastructure and increasing accessibility.
\end{abstract}

Keywords: values, power, carving, tuo house, culture

\begin{abstract}
ABSTRAK
Nilai-nilai kekuasaan yang dimiliki oleh para pemangku adat atau ninik mamak pada masyarakat Melayu Bungo terlihat dari kedudukan beliau dalam rumah tuo. Rumah Tuo merupakan salah satu peninggalan kebudayaan dari melayu kuno, Rumah Jambi identik dengan adat Melayu Kuno. Metode yang digunakan dalam penelitian ini penelitian ini adalah metode penelitian kualitatif yang bersifat studi kasus. Infroman penelitian dipilih dengan metode purposive sampling. Hasil penelitian menemukan bahwa nilai-nilai kekuasaan dalam ukiran rumah tuo di Kelurahan Kampung Baruh Kecamatan Tabir Kabupaten Merangin terlihat dari ukiran yang ada pada ornament rumah tuo, diantaranya: Ukiran Keluk Paku (Kayu Pakis) bermakna setiap pelaku pembangunan (pemimpin) harus dapat mengayomi atas fungsi dan peranan yang diembannya, Ukiran Tampuk Manggis artinya orang suku bathin menunjukan kesopanan keramahan bermuka manis kepada siapapun tamu yang datang. Ukiran Tali Ikat filosofi satu ikatan yang kuat dan kekeluargaan yang erat dalam keluarga, Ukiran Mensinding Gulung Paku (Pakis) menunjukan batas antara nenek mamak, tetua adat, tokoh agama dengan ruang keluarga dan tamu, Ukiran Akar kekait orang suku bathin jika menikah anaknya dari unsur (dijodohkan) dari keluarga sendiri atau dari suku yang sama. Upaya Pemerintah Daerah Kabupaten Merangin dalam melestarikan keberadaan rumah tuo di Kelurahan Kampung Baruh Kecamatan Tabir Kabupaten Merangin, diantaranya membuat daya tarik kawasan, peningkatan sarana dan prasarana serta peningkatan aksesibilitas.
\end{abstract}

Kata kunci: nilai-nilai, kekuasaan, ukiran, rumah tuo, kebudayaan.

Indexed: 


\section{GDVERNANCE: Jurnal IImiah Kajian Politik Lokal dan Pembangunan \\ ISSN: 2406-8721 (Media Cetak) dan ISSN: 2406-8985 (Media Online) \\ Volume 7 Nomor 4 Juni 2021}

\section{PENDAHULUAN}

Nilai-nilai kekuasaan yang dimiliki oleh para pemangku adat atau ninik mamak pada masyarakat Melayu Bungo terlihat dari kedudukan beliau dalam rumah tuo. Rumah Tuo merupakan salah satu peninggalan kebudayaan dari melayu kuno, Rumah Jambi identik dengan adat Melayu Kuno. Didalam rumah tergambar tentang hubungan manusia dalam sebuah keluarga inti, keluarga besar, dan masyarakat. Ada penghormatan terhadap pemangku adat atau ninik mamak, jaminan perlindungan bagi anak-anak, hidup berkecukupan dalam keluarga, dan keharmonisan sosial dalam masyarakat.

Salah satu nilai kekuasaan dalam konstruksi rumah tuo di Kelurahan Kampung Baruh Kecamatan Tabir Kabupaten Merangin terlihat dari posisi ruang yang pertama yang digunakan ruang pertemuan dengan lantai yang dibagi menjadi tiga bagian. Antara bagian satu dengan lainnya dipisahkan dengan sekat kayu berukuran $10 \mathrm{~cm}$. Lantai yang agak tinggi disebut Balai Melintang diperuntukkan untuk pemangku adat atau Ninik Mamak dan ulama. Sedangkan lantai tengah untuk keluarga, serta lantai lorong yang menuju ke ruang kedua diperuntukkan bagi para pekerja.

Posisi tempat duduk orang-orang tersebut menunjukan nilai-nilai kekuasaan yang diakui oleh masyarakat di Kelurahan Kampung Baruh dari tempo dulu hingga sekarang, dimana ninik mamak dan ulama merupakan orang yang dihormati dan memiliki posisi tertinggi dalam status sosial kemasyarakatan, kemudian diikuti oleh pihak keluarga, dan pada lantai lorong diberikan kedudukan bagi para pekerja, yang secara status sosial lebih rendah.

Selain itu pada konstruksi rumah tuo terdapat beberapa tiang, tiang utama berbentuk persegi (segi $6,8,12,16$, dan 18). Bentuk tiang segi enam tentunya berbeda dengan segi delapan, segi dua belas dan seterusnya, semakin banyak segi pada tiang semakin besar diameter dan kekuatannya, selain menunjukan besaran diameter dan kekuatannya, bentuk segi pada tiang ternyata juga menunjukan status sosial pemilik rumah. Pemilih rumah tuo dengan bentuk tiang segi lebih banyak memiliki status yang lebih tinggi daripada bentuk tiang segi lebih sedikit. Pemilik rumah ini adalah orang yang sangat dihormati dalam masyarakat tersebut, seperti pemuka adat; alim ulama, ninik mamak; dan cerdik pandai. Hal ini mengindikasikan rumah dengan tiang berbentuk segi banyak hanya diperuntukkan bagi kalangan tertentu, tidak setiap orang bisa membuatnya.

Dilihat dari sejarah, Rumah Tuo ini dibuat oleh beberapa leluhur melayu yang terdiri dari 19 keluarga pelarian dari Koto Rayo yang bersama- sama membangun rumah ini. rumah-rumah tersebut dibangun oleh para leluhur warga Melayu Kuno yang sebelumnya menempati kampung lain di kecamatan yang sama. Tujuannya mencari tempat aman. Permukiman ini kemudian semakin berkembang. Namun, dalam perkembangannya, masyarakat tetap menjaga kelestarian rumah adat. Warga yang hendak membangun rumah baru juga mengacu kepada arsitektur adat setempat. Hanya saja kayu yang digunakan tidak lagi kayu kulim karena sudah semakin langka, Meski terkesan tidak jauh berbeda dari arsitektur rumah adat Minang, ciri khas rumah adat Jambi dapat ditemukan pada sudut atapnya yang dipasang tanduk kambing, yaitu kayu bersilang menghadap ke dalam. Tanda ini menandakan rumah tersebut memiliki nini mamak sebagai pengayom. Setelah jadi satu rumah, mereka bersama-sama membangun rumah keluarga yang Iain. Begitu seterusnya sampai tuntas dibangun 19 rumah, para leluhur bersepakat untuk menetapkan 20 tiang dipancang untuk menegakkan sebuah rumah.

Atapnya semula dibuat dari daun rumbia, namun kini telah berganti seng karena dianggap dapat lebih efesien dibandingkan atap rumbia yang lebih gampang rusak. Kolong rumah dijadikan gudang penyimpanan kayu bakar untuk memasak dan tempat ternak. Rumah tuo melebar tampak dari muka, dengan tiga jendela besar yang selalu dibuka pemiliknya hingga sore. Begitu cermatnya nenek moyang mereka, sampai-sampai etika diatur melalui penataan jendela. etika bertamu diatur oleh hukum adat.

Rumah Tuo sebagai Rumah tradisional yang terdapat dalam kehidupan masyarakat Kampung Baruh dengan sendirinya merupakan gambaran kebudayaan yang dimiliki oleh masyarakat setempat. Selain karekteristik yang sudah diuraikan diatas rumah tuo juga dikatakan sebagai rumah adat dikarenakan Rumah Tuo sering digunakan sebagai tempat dilaksanakannya upacara-upacara adat pertemuan-pertemuan adat, musyawarah, pengambilan keputusan dan Rumah Tuo juga banyak mengandung nilai-nilai budaya masyarakat yang banyak menggambarkan kehidupan masyarakat Kampung Baruh pada masa lalu hingga saat ini. Masyarakat Kampung Baruh ini (Orang Bathin) di

Indexed: 


\section{GDVERNANCE: Jurnal IImiah Kajian Politik Lokal dan Pembangunan \\ ISSN: 2406-8721 (Media Cetak) dan ISSN: 2406-8985 (Media Online) \\ Volume 7 Nomor 4 Juni 2021}

Kelurahan Kampung Baruh ini Rumah Tuo masih sangat dilestarikan keberadaannya serta fungsinya dałam menjalani kehidupan sehari-hari, meskipun ada juga fungsi-fungsi rumah tersebut yang pada masa lalu tidak lagi dijalankan dałam kehidupan sekarang.

\section{METODE}

Dalam penelitian ini yang menjadi lokasinya adalah Kelurahan Kampung Baruh Kecamatan Tabir Kabupaten Merangin. Alasan memilih lokasi ini dikarenakan peneliti melihat bahwa di Kelurahan Kampung Baruh merupakan salah satu kelurahan yang masih mempertahankan keberadaan rumah tuo di Kecamatan Tabir. Penelitian ini dilaksanakan pada bulan April 2020 sampai dengan Juni 2020. Metode yang digunakan dalam penelitian ini penelitian ini adalah metode penelitian kualitatif yang bersifat studi kasus. Penelitian studi kasus (Case Study) adalah penelitian tentang suatu objek penelitian yang berkenan dengan suatu fase spesifik atau dari keseluruhan personalitas ${ }^{1}$. Menurut Bogdan dan Taylor, metode kualitatif adalah prosedur penelitian yang menghasilkan data deskriptif yang berupa kata-kata tertulis atau lisan dari orang-orang dan perilaku yang diamati. ${ }^{2}$ Teknik Pengumpulan Data menggunakan data primer dan data sekunder. Data primer adalah data yang diperoleh langsung dari informan. Yang termasuk data primer adalah transkrip hasil wawancara dan hasil temuan-temuan saat proses pelaksanaan penelitian. Data sekunder yaitu data yang diperoleh secara tidak langsung dari objek penelitian. Pengumpulan data sekunder dalam penelitian ini dengan cara penelitian kepustakaan dan pencatatan dokumen, yaitu dengan mengumpulkan data dan mengambil informasi dari buku-buku referensi, dokumen, foto, majalah, jurnal, artikel dan internet yang dianggap relevan dengan masalah yang diteliti.

Teknik pemilihan informan yang digunakan oleh peneliti dalam penelitian ini adalah dengan menggunakan metode purposive sampling (teknik penentuan sampel dengan pertimbangan tertentu), metode ini digunakan karena tidak semua orang memahami sejarah dan nilai yang terdapat pada rumah tuo. Informan dipilih orang-orang yang mengetahui arti dari ukiran-ukiran di Rumah Tuo. Berikut daftar informan:

Tabel 1. Daftar Informan

\begin{tabular}{|c|l|l|c|}
\hline No & \multicolumn{1}{|c|}{ Nama } & \multicolumn{1}{|c|}{ Jabatan } & Jumlah \\
\hline 1 & $\begin{array}{l}\text { Said Usman, } \\
\text { S.Pd., M.kom }\end{array}$ & $\begin{array}{l}\text { Kabid Kebudayaan pada Dinas Pendidikan } \\
\text { dan Kebudayaan Kabupaten Merangin }\end{array}$ & 1 \\
\hline 2 & M. Zain & Ketua Lembaga Adat Kampung Baruh & 1 \\
\hline 3 & Mutar, S.Pd.I & Tokoh Adat & 1 \\
\hline 4 & H. Ashari & Tokoh Masyarakat & 1 \\
\hline 5 & Janggot/Yunus & Tokoh Masyarakat & 1 \\
\hline 6 & Farida & Masyarakat & 1 \\
\hline 7 & Iskandar & Penjaga/Pemilik Rumah Tuo & 7 \\
\hline \multicolumn{2}{|r}{} \\
\hline
\end{tabular}

\section{PEMBAHASAN}

1. Nilai-Nilai Kekuasaan dalam ukiran rumah tuo di Kelurahan Kampung Baruh Kecamatan Tabir Kabupaten Merangin.

\section{Ukiran Keluk Paku (Kayu Pakis)}

Ukiran Keluk Paku (Kayu Pakis) memiliki filosofi "keluk paku kacang belimbing anak dipangku kemenakan dibimbing" yang bermakna bahwa kekuasaan harus memiliki tanggung jawab, yang tercermin dari seloko adat "anak dipangku, kemenakan dibimbing" yang mengandung makna bahwa

\footnotetext{
${ }^{1}$ Nawawi, Hadari, Metode Penelitian Bidang Sosial, Yogyakarta: Gajah Mada. University Press, 1992:66).

${ }^{2}$ Moleong, L. J. Metodologi Penelitian Kualitatif, Bandung : PT Remaja Rosdakarya 2004, hlm. 3 


\section{GDVERNANCE: Jurnal IImiah Kajian Politik Lokal dan Pembangunan \\ ISSN: 2406-8721 (Media Cetak) dan ISSN: 2406-8985 (Media Online) \\ Volume 7 Nomor 4 Juni 2021}

setiap pelaku pembangunan harus dapat mengayomi atas fungsi dan peranan yang diembannya. Hal ini sebagaimana diungkapkan oleh Bapak Iskandar selaku Penjaga/Pemilik Rumah Tuo:

“..banyak jenis ukiran yang terdapat di rumah tuo, hanya setiap rumah memiliki ukiran tersendiri berdasarkan kelas sosialnya sendiri. Diantaranya adalah Ukiran Keluk Paku (Kayu Pakis) memiliki filosofi "keluk paku kacang belimbing anak dipangku kemenakan dibimbing" yang mengandung arti setiap orang yang berada di rumah harus mendapatkan perhatian dan tanggungjawab bersama, baik itu anak sendiri maupun keponakan.."3

Pernyataan tersebut sesuai dengan apa yang diungkapkan oleh Bapak M. Zain selaku Ketua Lembaga Adat Kampung Baruh:

“..memang motif pada ukiran yang ada pada rumah tuo beragam, ada ukiran Keluk Paku (Kayu Pakis), yang mengandung arti tanggungjawab bersama sesuai seloko adat anak dipangku kemenakan dibimbing" yang mengandung arti bahwa tidak ada perbedaan antara anak maupun kemenakan, semuanya harus mendapat perhatian dari tuan rumah selaku pemegang kekuasaan dari rumah tuo.. ",

Kepemimpinan dalam masyarakat adat Melayu Jambi dicerminkan dalam seloko "berjenjang naik, bertangga turun". Seorang pemimpin diikuti dan dipatuhi oleh masyarakat. Pimpinan yang dimaksudkan dalam seloko ini bersifat umum, yang mengatur cara penghidupan dan kehidupan, baik dalam lingkungan keluarga maupun dalam kehidupan bermasyarakat dalam bentuk organisasi apapun.

\section{Gambar 1.}

\section{Ukiran Keluk Paku (Kayu Pakis)}

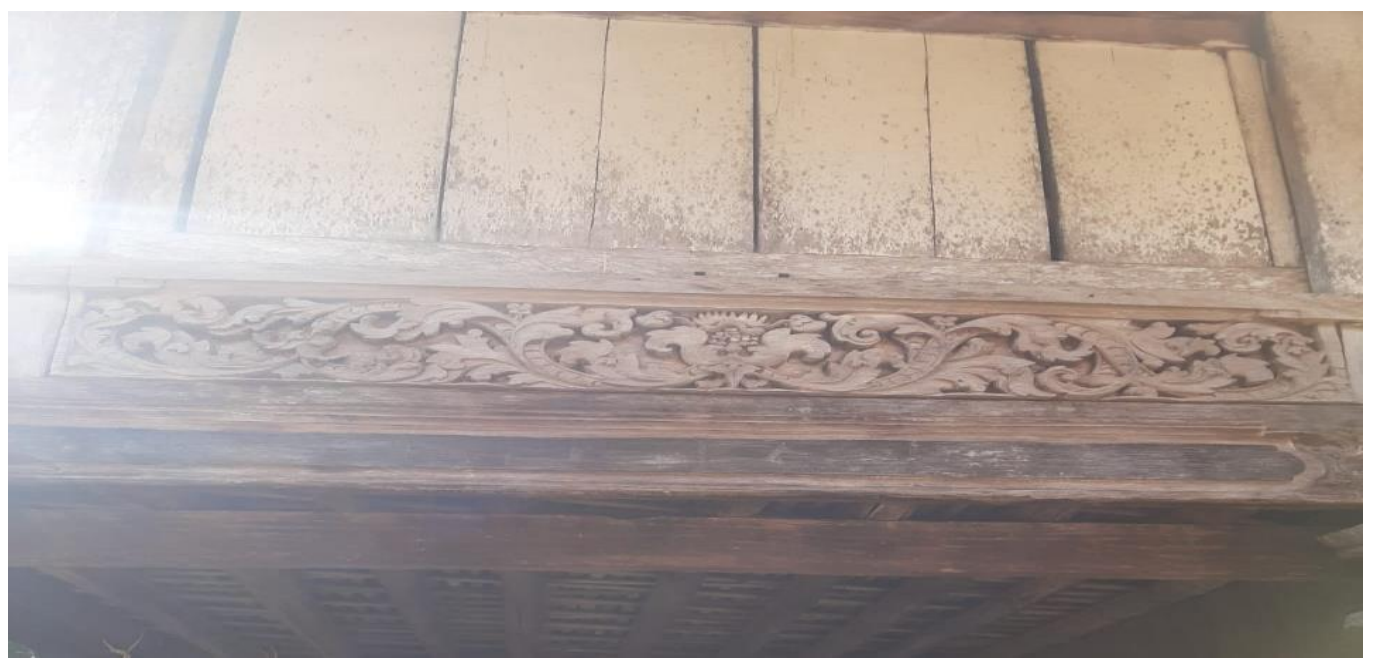

Sumber : Dokumen Penelitian, 2020

\footnotetext{
${ }^{3}$ Wawancara dengan Bapak Iskandar selaku Penjaga/Pemilik Rumah Tuo, tanggal 26 April 2020

${ }^{4}$ Wawancara dengan Bapak M. Zain selaku Ketua Lembaga Adat Kampung Baruh, tanggal 29 April 2020 


\section{GDVERNANCE: Jurnal IImiah Kajian Politik Lokal dan Pembangunan \\ ISSN: 2406-8721 (Media Cetak) dan ISSN: 2406-8985 (Media Online) \\ Volume 7 Nomor 4 Juni 2021}

\section{Ukiran Tampuk Manggis}

Ukiran Tampuk Manggis memiliki filosofi senyum. Yang artinya orang suku bathin menunjukan kesopanan keramahan bermuka manis kepada siapapun tamu yang datang.

\section{Gambar 2.}

\section{Ukiran Tampuk Manggis}

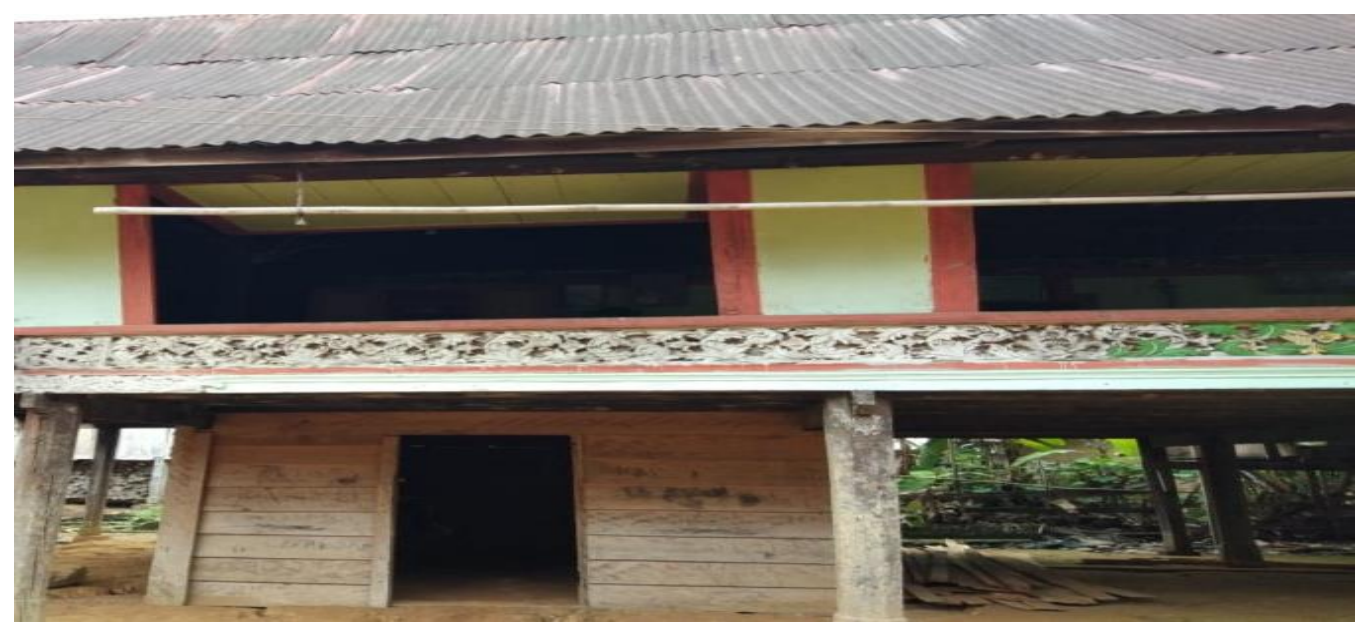

Sumber : Dokumen Penelitian, 2020

Sesuai dengan sifat hakiki kepemimpinan sendiri, maka cara pemakaiannya harus lemah lembut. Seorang pemimpin diharapkan dapat memimpin tanpa perlu mempergunakan cara-cara kasar, seakan-akan kepemimpinan semuanya berjalan dengan sendirinya. Tanda keselarasan dan keseimbangan yang sempurna adalah bahwa keadaan dapat dipertahankan tanpa masukan-masukan korektif kasar. Hal ini sebagaimana diungkapkan Bapak M. Zain selaku Ketua Lembaga Adat Kampung Baruh:

“..motif tampuk manggis mengajarkan bahwa pemilik rumah bukan orang yang suka marah-marah, bicara dengan suara keras dan memukul meja yang sebenarnya kuat, melainkan orang yang tenang, beradab dan tidak gelisah dan bingung. "Tudung manudung bak daun sirih, jahit menjahit bak daun pete, taub menaub bak benak ketam". (Tutup menutup seperti daun sirih, jahit menjahit seperti dauh petai, kait mengait seperti ketam) "Bak kuku dengan daging, bak emas dengan suaso, bak tali bapintal tigo, bak aur sayang ke tebing, tebing sayang ke aur, tebing runtuh aur tabao, bak parang catuk di tunggul, tunggul lapuk parang takucil”.(Seperti kuku dengan daging, seperti emas dengan suasa, seperti tapi berpilin tiga, seperti bambu sayang pada tebing, tebing sayang pada bambu, seperti parang melekat di pokok pohon, pokoknya lapuk parangnya lepas). "Yang kecik disayangi, yang besak dihormati”.(Yang kecil disayangi, yang besar dihormati) $)^{5}$

Rumah Tuo dibangun mengikuti bentuk kapal dengan dinding depan dan belakang miring untuk alasan ketahanan. Rumah Tuo memiliki struktur bangunan rumah panggung. Kolong Rumah Tuo yang tinggi berguna untuk mengindari binatang buas dan bencana banjir. Sekarang kolong tersebut digunakan untuk penyimpanan kayu bakar dan barang. Pintu masuk (pintu tegak) berada dibagian depan Rumah Tuo, sementara tangga masuk berada di sebelah pintu tegak. Hitungan anak tangga yang berjumlah ganjil dimulai dari takak, tanggo, kulintang, jatuh memiliki makna filosofis yakni, bahwa ketika menaiki tangga harapannya seseorang tersebut tidak akan jatuh ke bawah karena telah

\footnotetext{
${ }^{5}$ Wawancara dengan Bapak M. Zain selaku Ketua Lembaga Adat Kampung Baruh, tanggal 27 April 2020 


\section{GDVERNANCE: Jurnal IImiah Kajian Politik Lokal dan Pembangunan \\ ISSN: 2406-8721 (Media Cetak) dan ISSN: 2406-8985 (Media Online) \\ Volume 7 Nomor 4 Juni 2021}

menapakkan kakinya di atas (menapakkan kaki setelah mengucapkan kata jatuh). Serta memiliki bangunan tambahan di bagian belakang.

\section{Ukiran Tali Ikat}

Ukiran Tali Ikat mengandung filosofi satu ikatan yang kuat dan kekeluargaan yang erat dalam keluarga. ${ }^{6}$

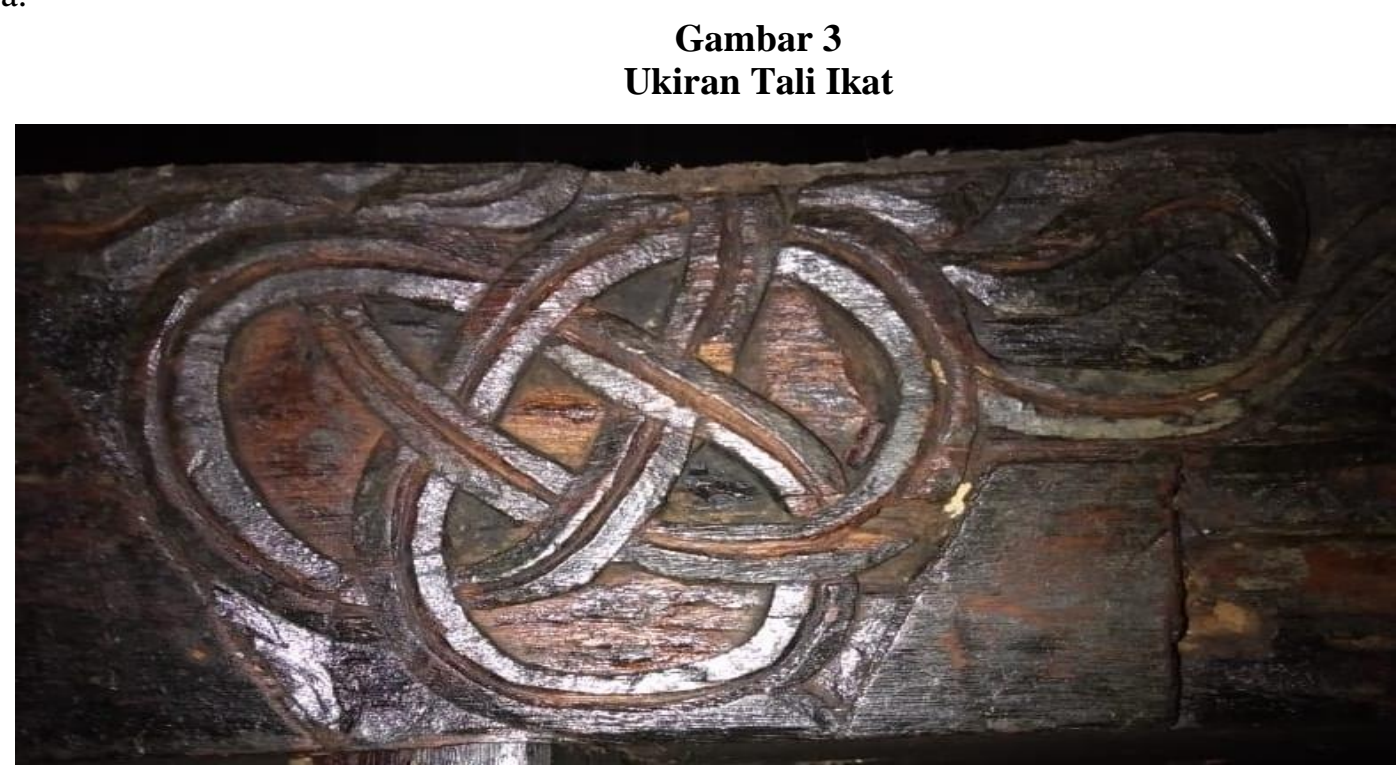

Sumber : Dokumen Penelitian, 2020

Sistem kekerabatan orang Batin adalah matrilineal (garis keturunan ditarik dari pihak ibu). Dalam kehidupan sehari-hari, orang Batin lebih dekat dengan kerabat pihak ibu daripada kerabat pihak ayah. Tetapi laki-laki tetap berperan sebagai kepala keluarga dalam rumah tangganya. Walaupun demikian pada masa sekarang kekerabatan itu lebih cenderung kepada bentuk bilateral, terlihat dalam pola bertempat tinggal setelah menikah. Pasangan baru akan bertempat tinggal sesuai dengan perjanjian sebelum menikah, bisa matrilokal, patrilokal, atau neolokal, akan tetapi garis keturunan tetap ditarik dari pihak ibu. Pada zaman dulu keluarga-keluarga inti tinggal bersama-sama dalam rumah besar membentuk keluarga luas yang mereka sebut piak. Beberapa piak yang merasa berasal dari satu nenek moyang dikelompokkan ke dalam suku. ${ }^{7}$

Orang Batin tinggal berkelompok dalam kampung-kampung yang mereka sebut dusun. Sebuah dusun dihuni oleh sejumlah keluarga luas yang disebut piak. Setiap piak dikepalai oleh seorang ninik mamak. Pemimpin dusun yang bergelar rio diangkat berdasarkan hasil musyawarah dari seluruh ninik mamak. Dalam menjalankan kepemimpinannya, rio didampingi oleh para ninik mamak. Dengan demikian segala keputusan rio haruslah diambil dengan persetujuan para ninik mamak dari piak yang ada di dusun tersebut. Pada masa dulu beberapa dusun tergabung menjadi satu dalam sebuah marga yang dipimpin oleh seorang depati, yaitu pejabat yang ditunjuk oleh Sultan Jambi.Pada masa sekarang status dusunsudah disejajarkan dengan desa dan berada di bawah kecamatan menurut aturan pemerintahan. $^{8}$

\section{Ukiran Mensinding Gulung Paku (Pakis)}

Ukiran Mensinding Gulung Paku (Pakis) menunjukan batas antara nenek mamak, tetua adat, tokoh agama dengan ruang keluarga dan tamu.

\footnotetext{
${ }^{6}$ Wawancara dengan Bapak M. Zain selaku Ketua Lembaga Adat Kampung Baruh, tanggal 27 April 2020

${ }^{7}$ Wawancara dengan Bapak M. Zain selaku Ketua Lembaga Adat Kampung Baruh, tanggal 27 April 2020

${ }^{8}$ Wawancara dengan Bapak M. Zain selaku Ketua Lembaga Adat Kampung Baruh, tanggal 27 April 2020
} 
GDVERNANCE: Jurnal IImiah Kajian Politik Lokal dan Pembangunan

ISSN: 2406-8721 (Media Cetak) dan ISSN: 2406-8985 (Media Online)

Volume 7 Nomor 4 Juni 2021

Gambar 4.

Ukiran Mensinding Gulung Paku (Pakis)

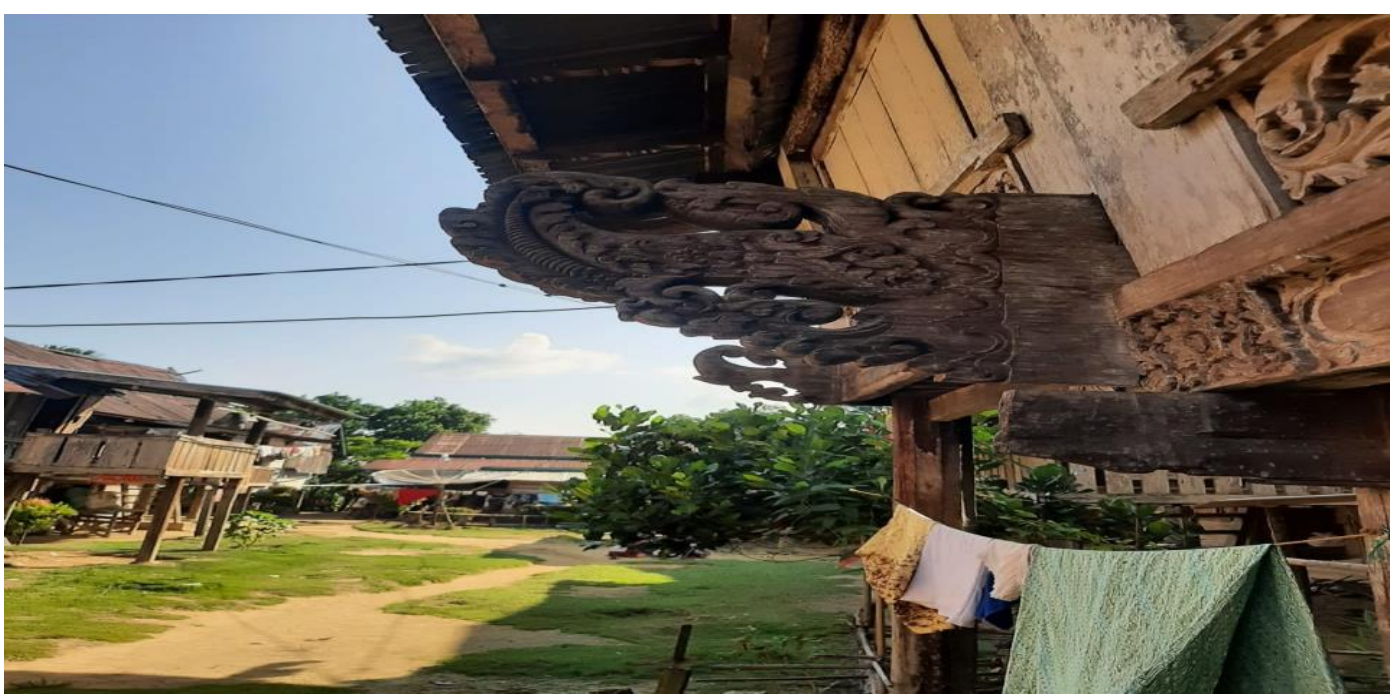

Sumber : Dokumen Penelitian, 2020

Menurut Bapak Iskandar selaku Penjaga/Pemilik Rumah Tuo Pembagian ruang di dalam Rumah Tuo ini lebih didasarkan pada segi kenyamanan dan fungsi ruang. Adapun pembagian ruangan tersebut secara umum ialah sebagai berikut: ${ }^{9}$

a. Pelamban merupakan teras yang digunakan untuk menyambut tamu pertama kali sebelum memasuki pintu rumah. Di sini terdapat kursi dan meja yang digunakan untuk bersantai atau menerima tamu. Rumah Tuo memiliki satu pelambandi bagian depan dan satu pelambanlagi di belakang rumah.

b. Ruang gaho ialah ruangan pertama saat masuk kedalam rumah lurus kebelakang, ruangan ini dulunya tempat seorang dubalang. Ruangan ini terdiri dari 3 bagian, yakni: paho merupakan tempat di bagian tengah untuk meletakkan labu yang berisi air, gaho merupakan tempat di paling bawah untuk meletakkan peralatan-peralatan untuk menangkap ikan misalnya jala dan penteh merupakan tempat yang paling tinggi tempat untuk meletakkan makanan pada saat ada kenduri dimana tidak ada yang boleh menyentuhnya sebelum tamutamu datang.

c. Serambi yang digunakan untuk menerima tamu undangan.

d. Ruangan tengah merupakan bagian ruangan yang diperuntukkan untuk berkumpul dan istirahat khusus keluarga. Ukuran ruangan ini lebih luas dari ruangan serambi. Pada ruangan ini terdapat alang tempat penyimpanan barang kerajinan anyaman berupa ambung untuk tempat membawa belanjaan dan mengambil air. Di dinding terdapat juga cangok untuk penangkal kekuatan jahat

e. Bandul sebagai pembatas antara serambi dan ruang tengah yang dipantangkan untuk dilangkahi oleh tamu. Pada rumah lainnya pantangan ini masih diberlakukan, tetapi pada rumah ini tidak diberlakukan lagi karena rumah ini difungsikan sebagai tempat penelitian. Sanksi yang dikenakan ialah kerbau, kambing, ayam, telur tergantung besar kecilnya kesalahan. Garis bandul jumlahnya pas 19 selemijak (orang duduk bersila)

f. Balai Malintang yaitu ruangan yang diutamakan untuk tempat duduk ninik mamak, cadik pandai dan alim ulama, dll. Bagian ruangan ini level lantai lebih tinggi dari pada ruangan yang lainnya. Ruangan ini diberi batasan yang disebut dengan istilah mensiding

\footnotetext{
${ }^{9}$ Wawancara dengan Bapak Iskandar selaku Penjaga/Pemilik Rumah Tuo, tanggal 26 April 2020 


\section{GDVERNANCE: Jurnal IImiah Kajian Politik Lokal dan Pembangunan \\ ISSN: 2406-8721 (Media Cetak) dan ISSN: 2406-8985 (Media Online) \\ Volume 7 Nomor 4 Juni 2021}

g. Manalam merupakan bagian ruangan yang dikhususkan untuk anak gadis atau pengantin baru. Ruangan ini merupakan ruangan pribadi yang tak sembarang orang dapat memasukinya. Biasanya ruangan ini akan ditempati oleh anak gadis yang paling tua

h. Balik manalam merupakan ruangan yang berada di sebelah kamar tidur atau manalam. Ruangan ini memiliki banyak fungsi. Biasanya ruangan ini dijadikan sebagai bilik cadangan tempat beristirahat oleh anggota keluarga selain dari anak gadis yang paling tua. Balik manalam ini hanya ditutup dengan kain tirai saja.

i. Bilik balai malintang merupakan ruangan yang digunakan sebagai tempat untuk berdiskusi terkait masalah yang cukup rumit oleh tetua yang paling tinggi jabatannya. Ruangan ini dikhususkan untuk para tetua yang memiliki jabatan yang paling tinggi

Sebenarnya ruang privat pada Rumah Tuo hanya kamar. Pintu gedang yang berukuran lebar sehingga bisa terlihat apa yang ada di rumah dari luar dan sebaliknya apa yang terjadi di luar rumah dapat dilihat dari dalam rumah merupakan suatu hal yang melambangkan bahwa Orang Bathin bersifat terbuka dan kalau ada masalah langsung to the point.

\section{Ukiran Akar kekait}

Ukiran Akar kekait yang artinya orang suku bathin jika menikah anaknya dari unsur (dijodohkan) dari keluarga sendiri atau dari suku yang sama. Hal ini sebagaimana diungkapkan oleh Bapak Iskandar selaku Penjaga/Pemilik Rumah Tuo:

“..umumnya masyarakat dulu terbiasa menikahkan anaknya dalam satu rumpun, sehingga terlihat sekarang kalau orang dusun memiliki hubungan kekeluargaan antara satu sama lain, hal ini disebabkan adanya perjodohan yang dilakukan oleh masyarakat zaman dahulu.." $" 10$

\section{Gambar 6}

\section{Ukiran Akar kekait}

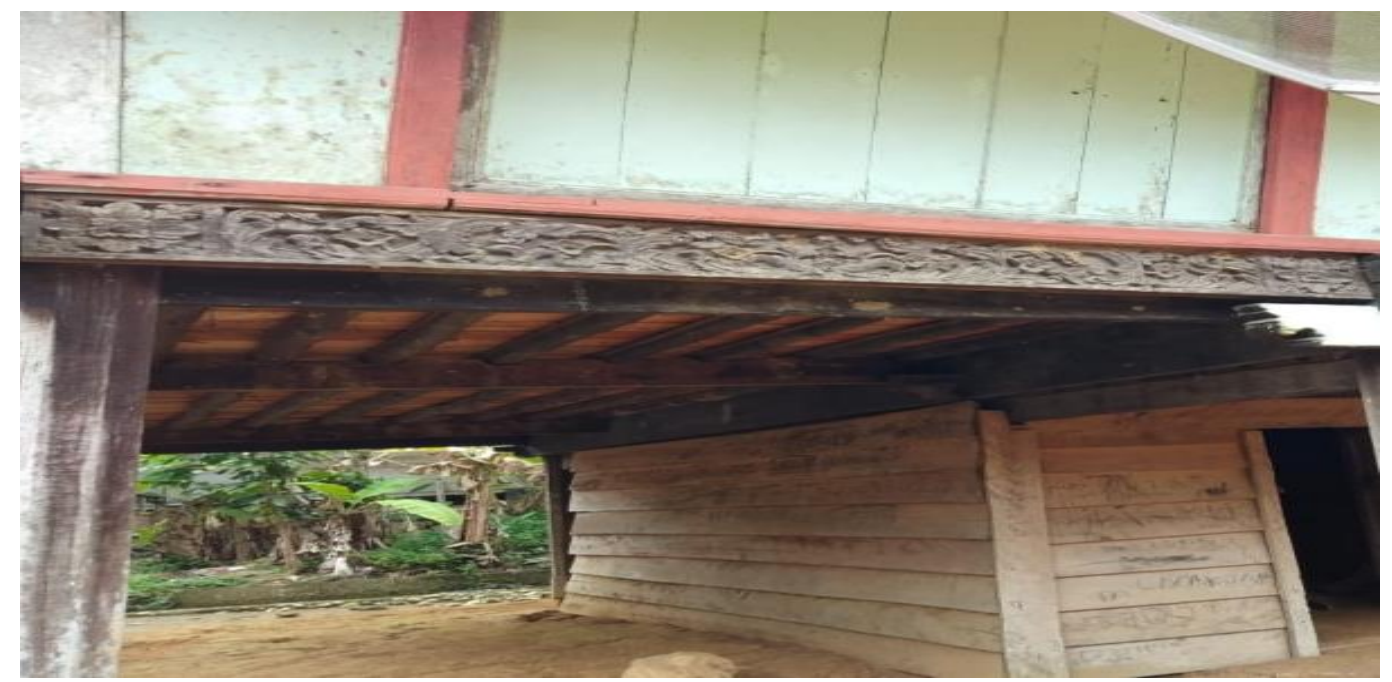

Sumber : Dokumen Penelitian, 2020

\section{Upaya Pemerintah Daerah Kabupaten Merangin dalam melestarikan keberadaan rumah tuo di Kelurahan Kampung Baruh Kecamatan Tabir Kabupaten Merangin}

\section{Melakukan Konservasi}

Kawasan rumah tuo sebagai kawasan konservasi memiliki potensi pengembangan sebagai wisata pedesaan dan dalam identifikasi disini wilayah perencanaan berada di Kelurahan Kampung Baruh tepatnya di RT 01 yang didalamnya terdapat $\pm 61 \mathrm{kk}$ serta $264 \mathrm{kk}$ dan memiliki luas $\pm 400 \mathrm{~m}^{2}$.

${ }^{10}$ Wawancara dengan Bapak Iskandar selaku Penjaga/Pemilik Rumah Tuo, tanggal 26 April 2020 


\section{GDVERNANCE: Jurnal IImiah Kajian Politik Lokal dan Pembangunan \\ ISSN: 2406-8721 (Media Cetak) dan ISSN: 2406-8985 (Media Online) \\ Volume 7 Nomor 4 Juni 2021}

Penetapan kawasan dengan penanganan konservasi didalamnya karena pernah masuk sebagai benda cagar budaya/ situs yang dilindungi dalam UU-RI nomor 5 tahun 1992 yang terdapat di Provinsi Jambi. Hal ini sebagaimana diungkapkan oleh Bapak Said Usman, S.Pd., M.kom selaku Kabid Kebudayaan pada Dinas Pendidikan dan Kebudayaan Kabupaten Merangin:

"..untuk melestarikan keberadaan rumah tuo di Kelurahan Kampung Baruh

Kecamatan Tabir Kabupaten Merangin maka kita melakukan konservasi, karena kita menyadari bahwa rumah tuo ini masuk sebagai benda cagar budayal situs yang dilindungi dalam UU-RI nomor 5 tahun 1992 yang terdapat di Provinsi Jambi.. "11

Beliau melanjutkan:

“..karena adany konservasi yang dilakukan oleh Pemerintah Daerah, maka kita lakukan juga promosi wisata cagar budaya, dengan adanya wisata tersebut tentu Rumah Tuo ini akan dipelihara dengan baik dan dilestarikan keberadaanya, jika tidak dilakukan promosi tersebut orang tidak akan datang, dan rumah tuo akan hancur dengan sendirinya.." 12

Pernyataan tersebut menunjukan adanya upaya Pemerintah Daerah Kabupaten Merangin melestarikan keberadaan rumah tuo dengan melakukan konservasi, seletah itu dipromosikan sebagai objek wisata budaya yang pada akhirnya akan dipelihara sendiri oleh masyarakat sebagai warisan peninggalan sejaharah masyarakat pada masa lalu. Menurut Bapak Bapak Said Usman, S.Pd., M.kom selaku Kabid Kebudayaan pada Dinas Pendidikan dan Kebudayaan Kabupaten Merangin tidak hanya rumah tuo tersebut tetapi segala sesuatu yang melekat pada sejarah rumah tuo terdapat potensi daya tarik wisata sejarah dan budaya berupa: ${ }^{13}$

\section{Peningkatan Sarana dan Prasarana}

Berdasarkan hasil wawancara dengan Bapak Said Usman selaku Kabid Kebudayaan pada Dinas Pendidikan dan Kebudayaan Kabupaten Merangin diketahui bahwa ketersediaan sarana pokok yang telah ditetapkan sesuai dengan karakteristik kawasan peruntukan pariwisata berdasarkan Peraturan Menteri Pekerjaan Umum no 41/PRT/2007 untuk Kawasan Rumah Tuo berupa sarana pendukung pariwisatanya belum banyak terpenuhi seperti pusat informasi, pusat cinderamata, rumah makan, kantor pengelola serta tempat rekreasi serta hiburan dan untuk standar prasarana yang dibutuhkan berdasarkan cheklist telah terpenuhi:

“..kita menyadari bahwa sarana dan prasarana yang terdapat di rumah tuo masih minim, maka perlu kita tingkatkan, kita sadar betul pusat informasi masih terbatas, cinderamata belum ada, rumah makan sebagai tempat singgah pengunjung juga belum ada, serta kantor pengelola juga belum, namun sudah mulai melakukan upaya peningkatan dengan memberikan petunjuk arah bagi masyarakat luar Merangin yang ingin berkunjung ke rumah tuo.." 14

Pernyataan tersebut mengambarkan kondisi yang sebenarnya, namun telah ada upaya dari Pemerintah Daerah Kabupaten Merangin untuk meningkatkan sarana dan prasarana, diantaranya dengan memberikan papan nama lokasi serta penunjuk arah di Jalan Raya sebagai penanda bagi masyarakat di Luar Daerah ketika ingin berkunjung ke Rumah Tuo. Dari ketersediaan sarana dan prasaran pariwisata pada Kawasan Rumah Tuo dilakukan penilain terhadap jumlah sarana dan prasarana eksisting saat ini serta kondisi pelayanannya dan didapatkan untuk sarana peribadatan perlu diperbaiki dan wc perlu untuk ditingkatkan pelayanannya terutama air bersih didalamnya serta

\footnotetext{
${ }^{11}$ Wawancara dengan Bapak Said Usman, S.Pd., M.kom selaku Kabid Kebudayaan pada Dinas Pendidikan dan Kebudayaan Kabupaten Merangin, tanggal 30 April 2020

12 Wawancara dengan Bapak Said Usman, S.Pd., M.kom selaku Kabid Kebudayaan pada Dinas Pendidikan dan Kebudayaan Kabupaten Merangin, tanggal 30 April 2020

${ }^{13}$ Wawancara dengan Bapak Said Usman, S.Pd., M.kom selaku Kabid Kebudayaan pada Dinas Pendidikan dan Kebudayaan Kabupaten Merangin, tanggal 30 April 2020

${ }^{14}$ Wawancara dengan Bapak Said Usman, S.Pd., M.kom selaku Kabid Kebudayaan pada Dinas Pendidikan dan Kebudayaan Kabupaten Merangin, tanggal 30 April 2020
}

Penerbit:

LKISPOL (Lembaga Kajian Ilmu Sosial dan Politik)

redaksigovernance@gmail.com//admin@1kispol.or.id

Indexed: 


\section{GDVERNANCE: Jurnal IImiah Kajian Politik Lokal dan Pembangunan \\ ISSN: 2406-8721 (Media Cetak) dan ISSN: 2406-8985 (Media Online) \\ Volume 7 Nomor 4 Juni 2021}

prasarana berupa persampahan, drainase belum berjalan secara baik. Hal ini sebagaimana disampaikan oleh Bapak Said Usman, S.Pd., M.kom selaku Kabid Kebudayaan pada Dinas Pendidikan dan Kebudayaan Kabupaten Merangin:

“..kita tidak bisa menutup mata, memang sarananya masih sangat terbatas, rumah tuo ini kan bukan satu, tapi suatu kawasan dusun, sehingga sarana pendukung seharus memang harus menjadi perhatian besama, seperti WC, sarana air bersih, persampahan, drainasenya juga harus kita bangun, jika sarana pendukung ini tidak ada, maka keberadaan rumah tuo ini akan punah sebab tidak dijaga mandiri oleh masyarakat atau pemiliknya.." $" 15$

Pernyataan tersebut menunjukan adanya kesadaran dari Pemerintah Daerah akan terbatasnya sarana pendukung untuk kawasan Rumah Tuo Kampung Baru, hanya saja kesadaran tersebut tidak didukung oleh upaya maksimal dari Dinas Pendidikan dan Kebudayaan Merangin untuk mendorong Dinas Pekerjaan Umum serta Dinas Perumahan dan Pemukiman agar membangun fasilitas umum di Kawasan rumah tuo Kampung Baruh.

\section{Peningkatan Aksesibilitas}

Dari pusat ibu kota Kabupaten Merangin yaitu kota Bangko menuju Kec.Tabir dengan tujuan simpang Tabir memilik jarak tempuh sekitar 25 kilometer, dan waktu perjalanan sekitar \pm 30 menit karena berada di jalan utama lintas trans Sumatera sehingga aksesibilitas menuju simpang Tabir dapat ditempuh dengan lancar dan ketersediaan moda memiliki banyak pilihan. Hal ini sebagaimana diungkapkan oleh Bapak Said Usman, S.Pd., M.kom selaku Kabid Kebudayaan pada Dinas Pendidikan dan Kebudayaan Kabupaten Merangin:

“..rumah tuo ini tidak jauh dari ibu kota Kabupaten Merangin, hanya $25 \mathrm{~km}$, kalau ditempuh menggunakan kendaraan pribadi atau umum lebih kurang 30 menit, dan lokasinyapun tidak jauh dari lintas sumatera, sehingga sangat mudah sekali untuk diakses.." 16

Beliau melanjutkan:

“...kita telah mengupayakan akses yang mudah bagi masyarakat yang ingin mengunjungi keberadaan rumah tuo di Kelurahan Kampung Baruh Kecamatan Tabir Kabupaten Merangin, baik sebagai wisata budaya atau edukasi bagi para pelajar, dan Alhamdulilah kita telah melakukan rehab jalan menuju dusun Kampung Baruh ini, agar masyarakat mudah melewati jalan tersebut.."

Pernyataan tersebut menunjukan bahwa aksesibilitas dapat diketahui bahwa menuju kawasan rumah tuo dari jalur utama memiliki jarak yang dekat yaitu kurang lebih $3 \mathrm{~km}$, namun untuk kondisi jalan masih kurang baik karena masih terdapat beberapa bagian ruas jalan yang berlobang dan untuk moda transportasi saat ini yang tersedia berupa ojek . oleh sebab itu untuk meningkatkan kemudahan bagi para pengunjung yang datang menuju kawasan rumah dari identifikasi aksesibilitas diharapkan perlu adanya perbaikan akan kondisi jalan dan penyediaan moda khusus sehingga memudahkan pengunjung yang datang.

\footnotetext{
${ }^{15}$ Wawancara dengan Bapak Said Usman, S.Pd., M.kom selaku Kabid Kebudayaan pada Dinas Pendidikan dan Kebudayaan Kabupaten Merangin, tanggal 30 April 2020

${ }^{16}$ Wawancara dengan Bapak Said Usman, S.Pd., M.kom selaku Kabid Kebudayaan pada Dinas Pendidikan dan Kebudayaan Kabupaten Merangin, tanggal 30 April 2020

${ }^{17}$ Wawancara dengan Bapak Said Usman, S.Pd., M.kom selaku Kabid Kebudayaan pada Dinas Pendidikan dan Kebudayaan Kabupaten Merangin, tanggal 30 April 2020
}

Penerbit:

LKISPOL (Lembaga Kajian Ilmu Sosial dan Politik) redaksigovernance@gmail.com//admin@1kispol.or.id

Indexed: 


\section{GDVERNANCE: Jurnal IImiah Kajian Politik Lokal dan Pembangun \\ ISSN: 2406-8721 (Media Cetak) dan ISSN: 2406-8985 (Media Onlinє \\ Volume 7 Nomor 4 Juni 2021}

\section{KESIMPULAN}

1. Nilai-nilai kekuasaan dalam ukiran rumah tuo di Kelurahan Kampung Baruh Kecamatan Tabir Kabupaten Merangin terlihat dari ukiran yang ada pada ornament rumah tuo, diantaranya:
a. Ukiran Keluk Paku (Kayu Pakis)
b. Ukiran Tampuk Manggis
c. Ukiran Tali Ikat
d. Ukiran Mensinding Gulung Paku (Pakis)
e. Ukiran Akar kekait

2. Upaya Pemerintah Daerah Kabupaten Merangin dalam melestarikan keberadaan rumah tuo di Kelurahan Kampung Baruh Kecamatan Tabir Kabupaten Merangin, diantaranya:
a. Membuat daya tarik kawasan
b. Peningkatan Sarana dan Prasarana
c. Peningkatan Aksesibilitas
DAFTAR PUSTAKA
Candra Kusuma Putra, Ratih Nur Pratiwi, suwondo, Pengelolaan Alokasi Dana Desa Dalam Pemberdayaan Masyarakat Desa dalam Pemberdayaan Masyarakat Desa. Jurnal Administrasi Publik, vol I, No. 6.

Iman Sudiyat, Asas-asas Hukum Adat, liberty, Yogyakarta, 2000.

Juanda, 2004, Hukum Pemerinthan Daerah, Pasang Surut Hubungan Kewenangan Antara DPRD dan Kepala Daerah, PT. Alumni, Bandung.

Kaelan, 2004, Pendidikan Pancasila, Paradigma, Yogyakarta.

Kamus Besar Bahasa Indonesia, Medan: Bitra Indonesia, 2013.

Moleong, L. J. Metodologi Penelitian Kualitatif, Bandung : PT Remaja Rosdakarya 2004.

Nawawi, Hadari, Metode Penelitian Bidang Sosial, Yogyakarta: Gajah Mada. University Press, 1992.

Otje Salman Soemadiningrat, Rekonseptuaisasi Hukum Adat Kontemporer, Alumni, Bandung.

R. Bintaro, Dalam Interaksi Desa - Kota dan Permasalahannya (Jakarta: Ghalia Indonesia, 1989).

Suharsimi Arikunto, Prosedur Penelitian: Suatu Pendekatan Praktik, Jakarta: Rineka Cipta, 2006, (Edisi Revisi VI)

Suroyo Wingjodipuro, Pengantar dan Azas-azas Hukum Adat, Alumni Bandung, 19

Syahrizal, Hukum Adat dan hukum Islam di Indonesia, Nadiya Foundation Nang siu .... h, Banda Ace, 2004.

Syaiful Rahman, 2004, Pembangunan dan Otonomi Daerah, Yayasan Pancur Siwah, Jakarta.

Widjaja, HAW. 2003. Pemerintahan Desa/Marga. PT. Raja Grafindo Persada. Jakarta.

Zamarkhrsyari, Teori-teori Hukum Islam dalam Fiqih dan Ushul Fiqh, Cipta Pustaka Media Perintis:

Bandung, 2013.

Undang-Undang Nomor 23 Tahun 2014 Tentang Pemerintah Daerah

Undang-undang Nomor 6 Tahun 2014 tentang Desa

Peraturan Menteri Dalam Negeri Nomor 5 Tahun 2007 tentang Pedoman Penataan Lembaga Kemasyarakatan

http://auliatasman.unja.ac.id/ auliatasmanunjaa/web/index.php/artikel/146-malpu-161-lembaga-adatdan-fungsinya

Wikipedia, Hukum Adat, http://id.wikipedia.org/wiki/, Diakses, 10 November 2016

Chandra Wesley S., Tiang-tiang Hukum Adat, http://candrawesly.blogspot.com/ html Diakses, 10 Novmeber 2016 